\title{
Enhanced Biometric Authentication System for Efficient and Reliable e-Payment System in Nigeria
}

\author{
F.O. Aranuwa \\ Department of Computer Science, \\ Adekunle Ajasin University, Akungba - Akoko, \\ Ondo State,Nigeria
}

\author{
G. B. Ogunniye \\ Department of Computer Science, \\ Adekunle Ajasin University, Akungba - Akoko, \\ Ondo State, Nigeria
}

\begin{abstract}
The recently introduced cashless economy with the cash-lite banking by the Central Bank of Nigeria (CBN) has engineered most Nigeria banks to introduce e-payment and e-transact solutions to support the policy. However, one of the major problems limiting the growth of this new move in Nigeria is the absence of secure and reliable e-payment systems. The problems associated with the implementation of a secure e-payment systems in the country stem from card thefts, internet fraud and identity theft e.t.c, which runs into millions of US dollars annually. This has adversely affected the integrity, development of e-commerce and the country's active participation in the international market. Hence, the need for a secured and reliable mechanism for a proficient implementation of e-payment system in the country. This paper is focused on securing reliable authentication scheme for e-payment system in Nigeria through effective biometric authentication technology.
\end{abstract}

\section{General Terms}

Security, Interswitch, Recognition, ATM, CBN

\section{Keywords}

Biometric Authentication, E-payment, Cashless economy, Internet banking, Modernization, Multi-stage

\section{INTRODUCTION}

The rapid and emerging growth of e-payment and its challenges in Nigeria has unavoidably increased the need for secured and reliable e-payment systems since the traditional payment system proved insufficient in handling the growing daily financial transactions across the globe. The cashless economy with the cash-lite banking recently introduced by the Central Bank of Nigeria (CBN) has engineered most Nigeria banks to introduce e-payment and e-transact solutions in support the policy. The new cashless policy was introduced for a number of key reasons, this include [6]:

i. To drive development and modernization of the nation's payment system in line with Nigeria's vision 2020 goal of being among the top 20 economies by the year 2020 .

ii. To reduce the cost of banking services and drive financial inclusion by providing more efficient transaction options and greater reach to the people. iii. To improve the effectiveness of monetary policies in managing inflation and driving economic growth in the country.

iv. In addition, the cashless policy was introduced not only with the sole aim of making the country a cashless economy but also with a view of reducing the cost of handling cash and tackle the problem of money laundering. Before the emergence of the new policy, Nigeria was predominantly a cash-based economy with a lot of cash in circulation [18]. This is because cash remains the predominant medium of payment in the country. Poor and inadequate e-commerce infrastructure, lack of trust, and illiteracy among others are identified factors that had been responsible for the high volume of cash in the country. These however, have affected the development of e-transaction and have restricted the ability of the country from exploring the potentials of international markets. Today in Nigeria, the consolidated 25 banks out of the 89 banks previously in existence are investing greatly in Information Technology (IT) infrastructure to implement various e-banking and e-payment solutions as means of satisfying the growing needs and demands of their customers. Since 2008, the use of epayment system in Nigeria has accounted for over N360 billion worth of transactions yearly, [3]. This is a pointer to the fact that the system is gaining ground in the country's economy. In 2011, the Central Bank of Nigeria took a giant stride towards the implementation of e-payment system in Nigeria with the introduction of cash-lite banking which was introduced and expected to become effective in all banks across the country by 2012 . The most predominantly used etransaction solution in the country before the new move was the Automated Teller Machine (ATM). According to Ayo and Ukpere (2010), ATM was responsible for about $89 \%$ (in volume) of all e-payment instruments since 2006 till introduction of the new policy. Moreover, since banks in Nigeria introduced card system as a medium of e-payment, report on e-banking system in Nigeria reveals that card technology is presently enjoying the highest popularity in Nigeria banking market. Interswitch statistics reveals that Nigeria has 30 million ATM card holders who conduct over 100 million transactions on the machine every month [2]. Meanwhile, ATM is only been commonly used for cash withdrawal and account balance checking in the country despite its other functions like fund/cash transfer, bill payments among others. As a result of this, it has done very little in reducing the amount of cash flow in the economy. 
Consequent upon the introduction of cash-lite banking in Nigeria, most of the banks has introduced internet banking solutions to strengthen its implementation. For instance, Skye Bank Plc, one of the leading bank in the country, has introduced several e-payment solutions such as Skye Point of Sale Terminal (POS), Skye Web Payment, Skye Direct Debits, Skye Collections and Remittances (SkyePAY) and Skye Internet Banking among others. Nonetheless, the wider patronage of ecommerce and e-payment solutions is dependent on the availability of a secured and trusted e-payment mechanism [12]. In view of this, adequate measures are therefore required to be in place for the security and reliability of e-payment systems in the country.

\subsection{Threats to the security of e-payment systems in Nigeria}

A number of security issues were identified as inhibiting factors to be addressed for wider patronage of e-payment solutions in Nigeria. Some of these factors includes: lack of sufficient network security and security of the system itself, Studies have also identified lack of trust as one of the major impediment to customer usage of online financial applications [12]; [15]; [16]. Generally, e-payment systems are exposed to the following threats, [11]: (a). Internet fraud, where Internet fraudsters hacking the bank details of a legitimate customer and using the same to make fraudulent transactions or an individual attacking or corrupting the data in the e-payment system to extort money from sponsoring financial institution or to cover up financial embezzlement. (b). Card theft problem, where an individual stealing customer's personal/card details and breaking into user's account in order to initiate unauthorized or fraudulent transactions and (c). Identity theft, where an individual using e-payment system to mask illegitimate or illegal transactions (e.g money laundering). Most of these threats are internally perpetrated (i.e. coming from an employee of an organization).

These challenges among others have to be tackled not only to catapult e-payment system into the mainstream of e-banking in the country, but also develop the concept of trust necessary for its wider acceptability and patronage. Several measures of ensuring the security of card technology, online transactions, internet banking and other e-commerce applications have been introduced by most of the banks in Nigeria. For instance, Magnetic Strip Cards have been upgraded to Euro-Visa-Master Cards Standard popularly known as Verve Card. The customers' data are recorded on the chip in the Verve card. The most recent one was the introduction of Biometric-Based ATM Cards by the First Bank of Nigeria Plc, taken the lead in this direction to be the first to introduce biometric ATM card in the country [16]).

However, in this work and publication, we present an archetype of improved biometric authentication technology using multi-stage recognition system of fingerprint and face for securing e-payment systems in Nigeria, especially in ATM and Online transactions. This is meant to supplement and improve the various security measures and technologies that have been deployed to secure e-payments in the country.

\section{LITERATURE REVIEW 2.1 Electronic Payment System}

Electronic payment system is refer to the automated processes of exchanging monetary values among parties in business transactions and transmitting this value over the information and communication technology (ICT) networks [4]. E-payment systems can be grouped into four major categories namely: Online Card Payment, Online Electronic Cash, Electronic Cheque and Smart Card based electronic payment system [17]. An appropriate e-payment system is meant to be employed for a particular category of etransaction. It is suggested however, that any reliable epayment system must be able to guarantee privacy, integrity, compatibility, efficiency, acceptability, convenience, mobility, and low financial risks among others, which are characteristics of a biometric system [5].

\subsection{Biometric Authentication Technology}

Biometric technology has become a foundation of an extensive array of highly secure identification and verification solutions, more importantly in the wake of heightened concern about security and rapid advancements in communication and mobility in our environments [5]. Biometrics promises to be the most reliable and secure means of authentication owing to the fact that it uses human distinctive physiological (e.g fingerprint, retina, iris etc) and behavioural (e.g voice, gait etc) characteristics for authentication [13]. Stanley et al (2009) described biometrics as the most secured and convenient authentication tool that cannot be stolen, forgotten, borrowed or forged. Their study identified a number of features that make biometrics a reliable authentication tools. These include: universality, uniqueness, permanence, collectability, performance, acceptability, and circumvention [20]. To secure any system, authentication is central. It entails verifying the identity of a system user to indicate that the user is who he/she claims to be. Authentication could be carried out in the following three ways: by something the user knows (such as password and pin), something the user has (security token and smart card) or something the user is (a physical or behavioural characteristics such as fingerprint, face, iris e.t.c) [14]; [19]. Meanwhile, (Ratha et al, 2010) have pointed out that passwords and card pins are no more enough to authenticate holders' identity, more so it could be stolen or forgotten. Hence, the need for an enhanced authentication mechanism that can consolidate security for efficient and reliable system using biometric technology.

Biometric technology does not only provide enhanced security but also avoids, in authentication applications, the need to remember multiple passwords and maintain multiple authentication tokens [1]; [10]. The technology is based on the fact that humans' physiological and behavioural characteristics are unique and can be used to uniquely identify them. These characteristics was considered fit into the e-transaction systems to authenticate the identity of its users. It basically indicates whether the users are what they claimed they are. In the operation of a biometric system, there are two distinct phases [9]. These are: enrolment and verification. In the first phase, identity information from 
users is added to the system in a database and in the second phase, live biometric information from users is compared with stored records in the database. A typical example of enrollment and verification process is shown in figure 1 below:

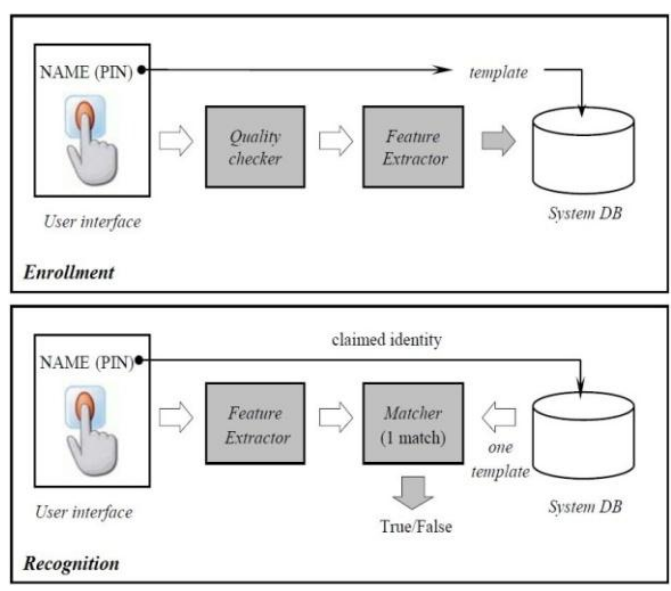

Figure 1: Typical Biometric Enrollment And Recognition Processes

However, it is worthy to note at this point that experimental studies has also shown that a biometric system that uses a single biometric trait for recognition has this propensity to contend with problems related to non-universality of the trait, spoof attacks, large intra-class variability, and noisy data. [21]; [7]. Hence, the need to combine more than one biometric trait in order to ensure secured, acceptable, effective, reliable and efficient e-payment systems. Figure 2 below shows a typical structure of how the two traits can be captured and fused in recognizing an identity.

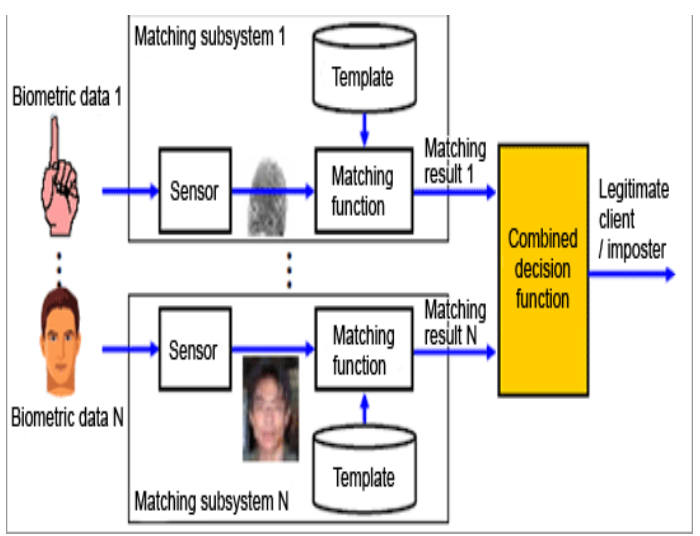

Figure 2. Showing A Typical Structure Of How The Two Traits Can Be Combined In Recognition An Identity. Adapted from

\section{http://www.hitachi.com/rd/yrl/people/bio/04.html 3. METHOD AND MATERIALS}

The major focus of this work and publication is to develop an enhanced biometric authentication technology for securing epayment systems in Nigeria for both ATM and online transactions using multi-stage recognition technique of fingerprint and face traits. The rationale behind the proposed system is to provide a system that guarantees the protection of a users' account, preventing unauthorized and fraudulent transactions (e.g card/identity theft). This is meant to enhance the various security measures and technologies that have been deployed to secure e-payments in the country. Figure 5 below represents the archetype of required functions and processes of the proposed system. To accomplish the archetype, the following methodology were adopted:

\subsection{Methodology}

The method employed in this research work included, data collection by survey from the banking industry, consultation, development of a platform for the biometric traits feature extraction (see samples in figure 3 and figure 4), and presentation of the archetype of the proposed enhanced epayment system in Nigeria (as shown in figure 5 below) respectively.

\subsection{System Components}

The client and server components of the proposed biometric e-payment application can be incorporated into ATM and any e-transaction solutions. The design purpose of a secured epayment is to find a balance between user convenience and security. Based on this, the requirements of the system are defined as follows: (i) prospective bank customer's registration, (fingerprint and face enrollment) with user's biodata and photograph integrated into a card to be issued to a user after registration (ii) verification during ATM and etransactions, and (iii) supply of Private Identification Number (PIN) or use fingerprint in the first stage and automatic face authentication by the system or ATM camera in the second stage. The system is designed to make use of the digital camera attached to the ATM or the webcam on the user's system or laptop to confirm whether the person in front of the camera is the legitimate owner of the bank account before transaction is allowed. If the system confirmed the user, transaction is allowed, else transaction is denied.

The activity diagram of the proposed archetype as presented in figure 5 below describes the functionality of the system as well as the interaction between the users and the system component. Finger conductivity and fingerprint pulse is suggested as techniques for handling the threats of fake biometrics at the sensor. An encrypted communication channel is also suggested to handle the possible threats of tampering with biometric feature representation. In addition to this, the biometric database should be stored in a secured environment so as to prevent the attacks that may arise from corrupting or tampering with the stored template by an intruder 


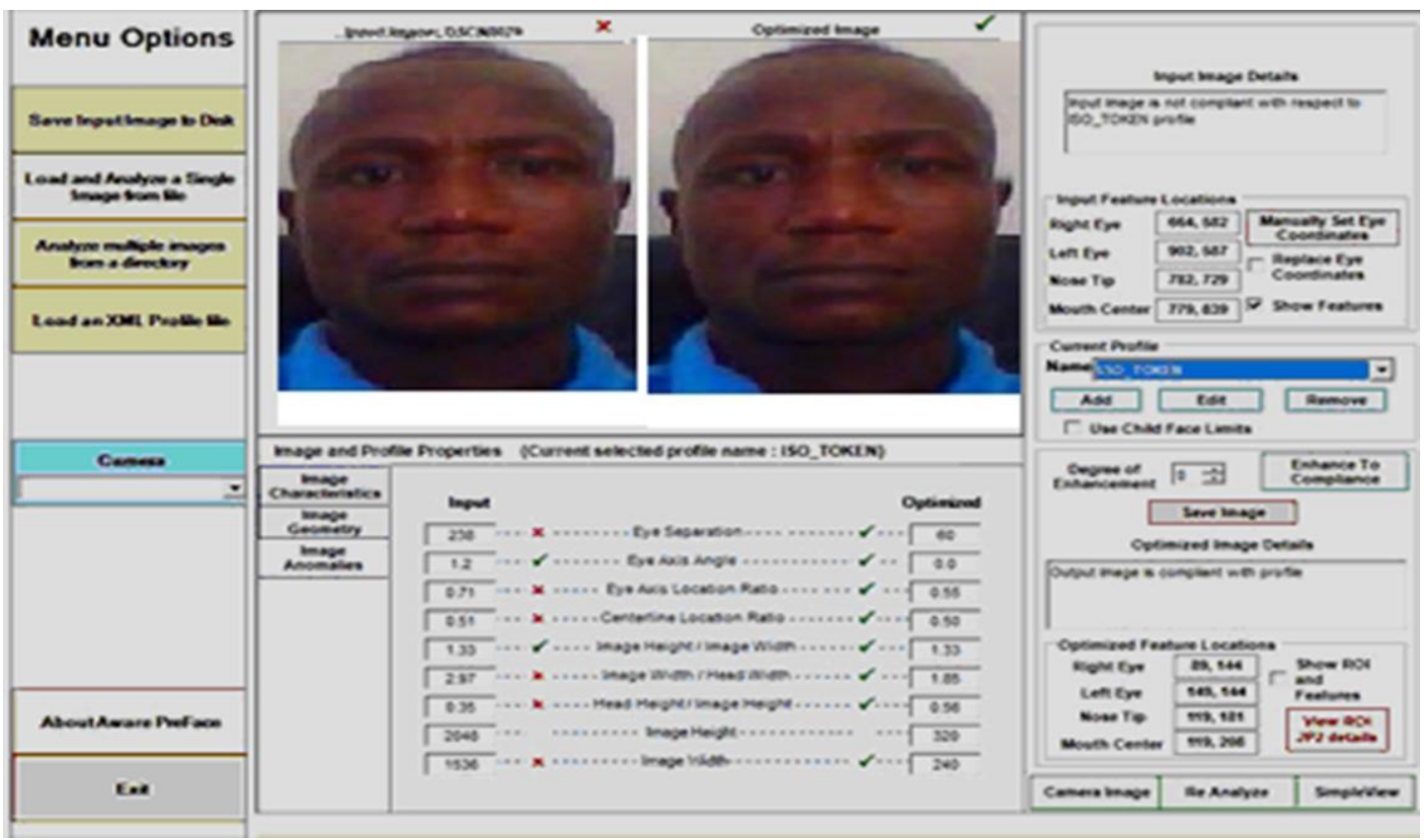

Figure 3: Sample of Pre-Face Feature Extraction Demo

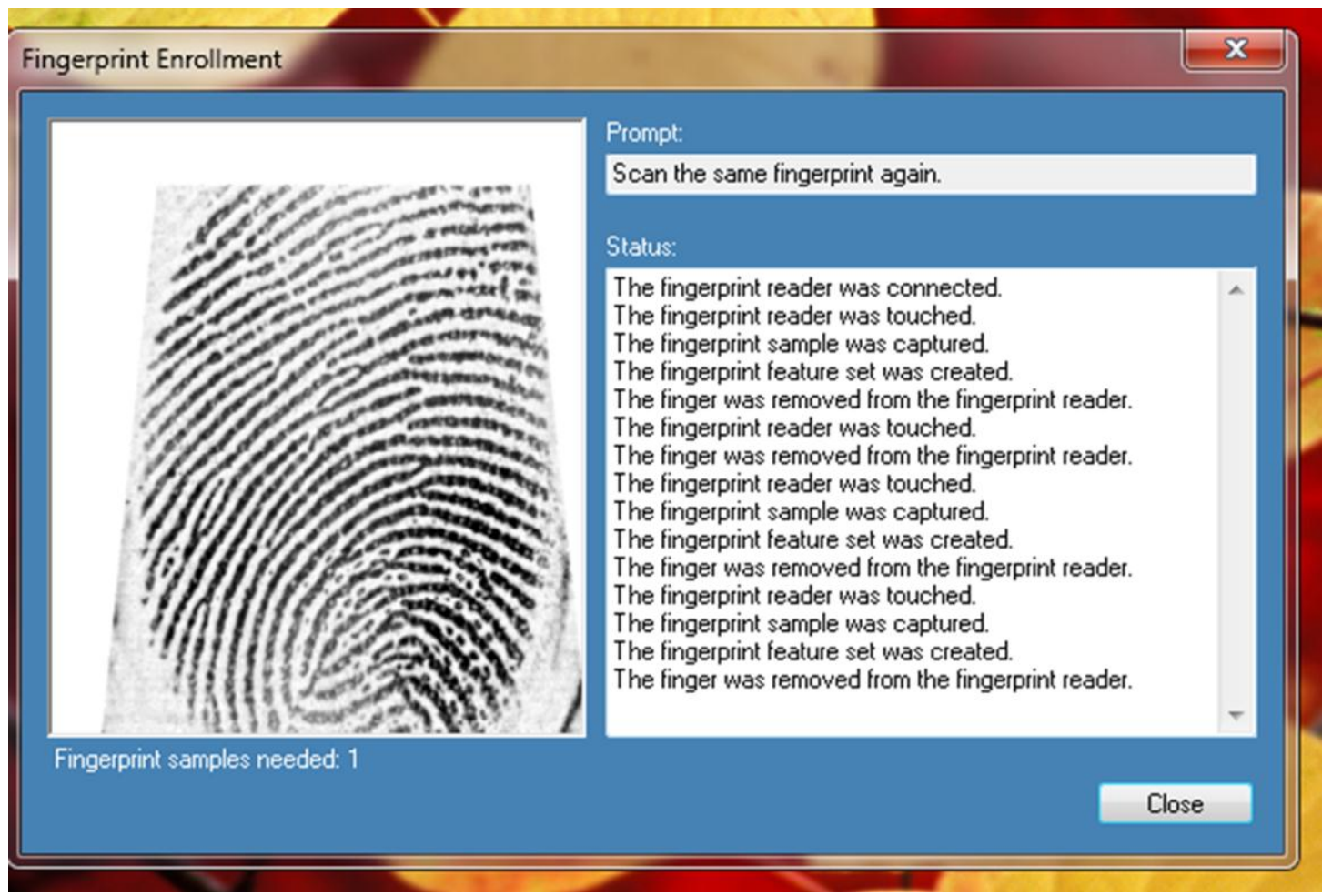

Figure 4: Sample Of Fingerprint Enrollment/Verification User Interface 


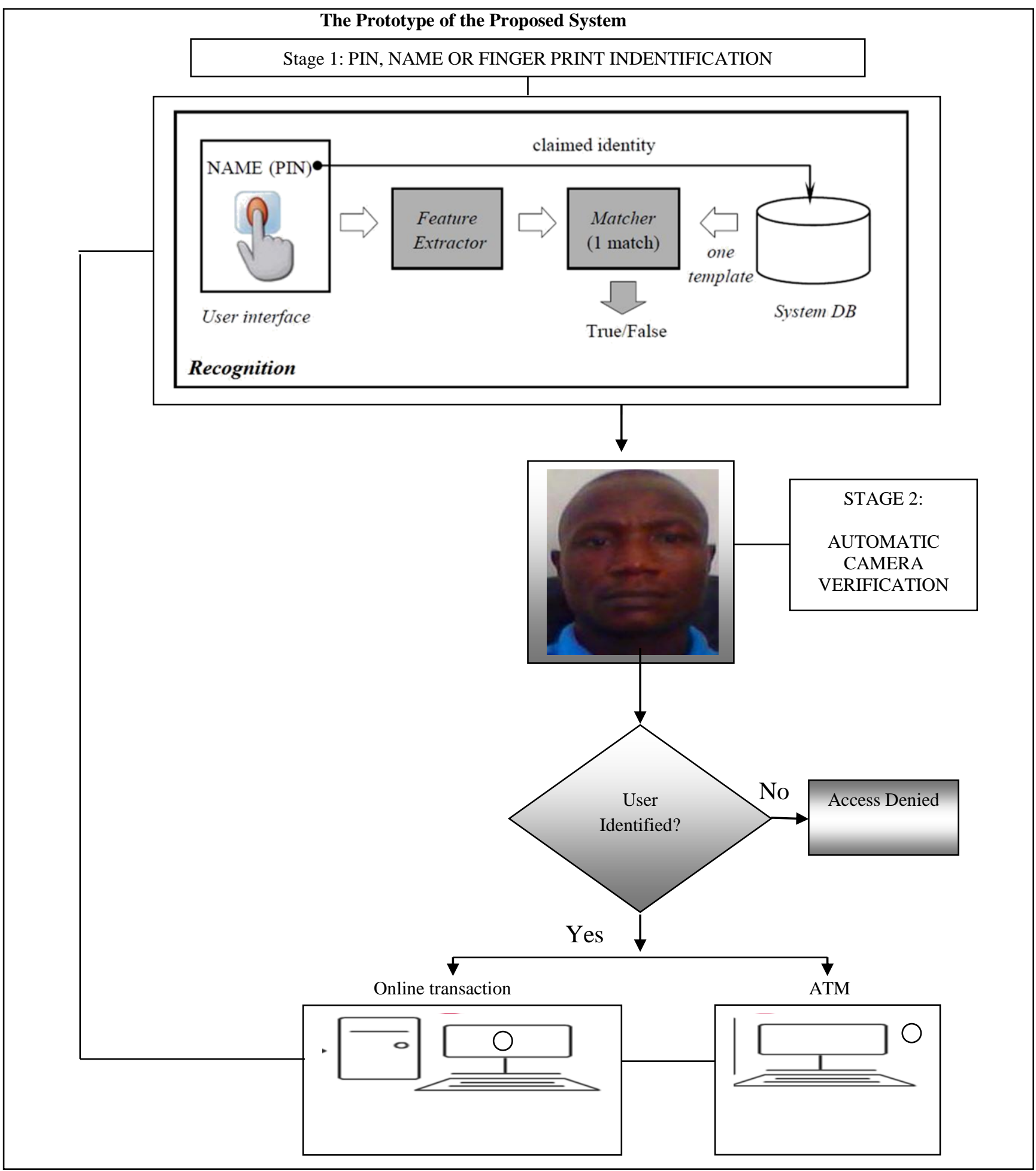

Figure 5: The Prototype Of The Enhanced Biometric Authentication System For Efficient And Reliable E-Payment System In Nigeria, Showing The Functionality And User Interaction

\section{CONCLUSION}

The rapid and emerging growth of e-transaction and its challenges in Nigeria has unavoidably increased the need for secured and reliable e-payment systems since the traditional payment system proved insufficient in handling the growing daily financial transactions across the globe. Hence, the need for the development of an enhanced biometric authentication epayment system that consolidates security as well as fraud prevention to support its implementation in the country. The archetype of the proposed system with multi-stage recognition mechanism designed in this work indicates and demonstrates that the enhanced approach will go a long way to eliminate 
security threats in e-payment systems and provides a reasonable degree of trust and acceptability needed for wider patronage of e-payment solutions in Nigeria. This we believe will revolutionize the country's economy, integrity and its participation in the international markets.

\section{REFERENCES}

[1] Aguilar, J. Z.,(2006): Adapted Fusion Schemes For Multimodal Biometric Authentication (Ph.D Thesis), Madrid: Universidad Politecnica De Madrid.

[2] Ajao, O. D. 2008. Interswitch Nigeria; Lower Your webpay Entry Fees, s.l.: Available: t:http:// www.davidajao.com/blog/2008 /02/17/interswitch-ltdlower-your-webpay-entry-fees/.

[3] Ayo, C. K, Adewoye J. O, and Oni A. A. 2010. The State of e-Banking Implementation in Nigeria: A Post Consolidation Review. Journal of Emerging Trends in Economics and Management Sciences (JETEMS), Scholarlink Research Institute Journals, 2010, 1(1), pp. 3745.

[4] Ayo C.K and. Ukpere, W. I. 2010. Design of a secure unified e-payment system in Nigeria: A Case Study. African Journal of Business Management,Available online at http://www.academicjournals.org/AJBM, 4(9), pp. 17531760.

[5] Biometrika, 2011. Introduction to Biometric Systems, s.1.: Biometrika (Italy) Available at:http://www.biometrika.it/ eng/wp_biointro.html.

[6] CBN, 2011.: Further Clarifications on Cash-less Lagos Project, (C) Central Bank of Nigeria, 2006-2011. All rights reserved.

[7] Damousis I. G. and Argyropoulos S. 2012. "Four Machine Learning Algorithms for Biometrics Fusion": Comparative Study. Applied Computational Intelligence and Soft Computing Volume 2012, Article ID 242401, 7 pages. Hindawi Publishing Corporation doi:10.1155/2012/242401

[8] Davidson, L. 2011. History and Technology of Fingerprinting, s.l.: HubPages Inc, Available at:http://leladavidson.hubpages.com/hub/History-andTechnology-of-Fingerprinting.

[9] Deravi, F. 1999. "Audio-Visual Person Recognition for Security and Access Control" Joint Information Systems Committee, University of Kent at Canterbury, Sept, 1999.
[10]Drygajio, A. 2011. "Information and Communication Security", LIDIAP Speech processing and Biometrics Group, Institute of Electrical Engineering, Ecole Polytechnique Federalede Lausanne (EPFL).http/scgwww.epfl.ch/courses

[11] Fajfar, M. 2004. Role and Security of Payment Systems in an Electronic Age, s.1.: IMF Institute Seminar on"Current Developments in Monetary and Financial Law" Available at:www.imf.org/external/np/leg/sem/2004/cdmfl/eng/faj.pd f.

[12] Flavian, C., Guinaliu, M., \& Torres, E. 2006. How bricksand-mortar attributes affect online banking adoption. The International Journal of Bank Marketing, 24(6), pp. 406423

[13] French, T. 2012. CIS050-6 Week 6: Biometrics. , Luton Campus, UK: University of Bedfordshire. Available at: http://breo.beds.ac.uk.

[14] Kay, R. 2005.. Biometric authentication, s.l.: Computerworld, Available at:http://www.computerworld.com/s/article/100772/Biomet ric_Authentication.

[15] Luarn, P. \& Lin, H.H. 2005 Towards an understanding of the behavioral intention to use mobile banking. Computers in Human Behavior, Volume 21, pp. 873-891

[16] MarketPlace, A. 2011. Nigerian bank deploys country's first biometric ATM, s.l.: ATM MarketPlace,Available on: http://www.atmmarketplace.com/article/179366/Nigerianbank-deploys-country-s-first-biometric-ATM.

[17] Mukherjee, A. \& Nath P. 2003. A model of trust in online relationship banking.. International Journal of Bank Marketing, 21(1), pp. 5-15.

[18] Nweze, C., (2012): Cash-Lite: Heavy transactions, less cash. The Nation News Paper, 0401.

[19] Ratha, N. K., Connell, J.H, and Bolle, R.M .2010. Enhancing Security and Privacy in Biometric Based Authentication System. IBM Systems Journal, 40(3), pp. 615-634.

[20] Stanley, P., Jeberson, W., and Klinsega V.V. 2009. Biometric Authentication: A Trustworthy Technology for Improved Authentication. 2009 International Conference on Future Networks, , pp. 171-175.

[21] Yadavi. S.S, Gothwal, J. K. and Singh. R. 2011. "Multimodal Biometric Authentication System: Challenges and Solutions". Global Journal of Computer Science and Technology. Volume XI Issues XVI Version 1, September, 2011. 